\title{
BREVE PAINEL DO CINEMA BRASILEIRO
}

\author{
O cinema nacional manteve-se atuante desde as primeiras décadas \\ do século, sobretudo com as produtoras Cinédia, Brasil Vita film, \\ Maristela e Vera Cruz, responsáveis pela maioria dos filmes \\ até os anos 50; depois o cinemanovismo deu forma a uma linguagem \\ que marcou os anos 60
}

Há hoje um enorme esforço por parte de nossos historiadores do cinema no sentido de levantar o perfil de identidade do cinema brasileiro. É uma difícil tarefa, que envolve necessariamente grande dose de paixão. Muitos historiadores estão se debruçando ou já se debruçaram sobre esse trabalho como Alex Viany, Paulo Emílio Salles Gomes, Jean Claude Bernadet, Maria Rita Galvão, para citar apenas alguns.

Em 1969 Paulo Emílio escreveu, ironicamente, num artigo para uma revista italiana: "O Brasil se interessa pouco pelo próprio passado. Essa atitude saudável exprime a vontade de escapar a uma maldição de atraso e miséria. $\mathrm{O}$ descaso pelo que existiu explica não só o abandono em que se encontram os arquivos nacionais, mas até a impossibilidade de se criar uma cinemateca. Essa situação dificulta o trabalho do historiador, particularmente o que se dedica a causas sem importância como o cinema brasileiro"'.

\section{A AUTORA}

Mary Enice Ramalho de Mendonça

Professora Doutora do Departamento de Comunicação e Artes da ECA-USP. Especialista em História e Cinema.
Estaremos nesse texto, algumas vezes, traçando um paralelo com o cinema latino-americano, considerando que os cinemas da América Latina se aproximam nas suas tendências, nas suas possibilidades, nos seus objetivos finais, mesmo que se distanciem nas suas histórias nacionais. Por exemplo, no que se refere aos projetos de industrialização do cinema. Poucos países puderam realizar, mesmo que precariamente, esse objetivo: primeiramente México, Argentina e Brasil e, mais recentemente, Cuba e Venezuela.

Dada a importância que o cinema tem na elaboração da imagem de seu povo, não apenas para o exterior, mas principalmente para seu público interno, podemos afirmar que a situação de crise em que vive a totalidade do cinema latino-americano, com exceção de Cuba, reflete a falta de atenção dos governos latino-americanos com relação às políticas cultur is de seus diversos países, incluindo-se, por exemplo, a conservação dos arquivos em diversas áreas da ciência, como a História.

Os interessados no cinema brasileiro têm lutado e denunciado a falta de "uma âncora" - no dizer de Ana Carolina ${ }^{2}$ - tal qual existe nos países desenvolvidos, como proteção necessária a este meio de comunicação.

1. GOMES, Paulo Emílio Salles. Pequeno Cinema Antigo. In: Cinema: trajetória no subdesenvolvimento. Rio de Janeiro: Embrafilme/Paz e Terra, 1980. p.29.

2. Diretora de Mar de rosas, Sonho de valsa etc., no Programa Roda Viva da TV Cultura. nov/94. 
No caso do cinema, há uma difícil recuperação das fontes, principalmente originais, que são os filmes, porque grande parte de nossa filmografia foi destruída.

Diferentemente da preocupação com a restauração de sua filmografia das primeiras décadas do século, que caracterizou, por exemplo, os EUA, interessados em valorizar sua história, o Brasil perde seus arquivos, por simples desdém governamental, por falta de projetos culturais.

Na medida em que, ao lado da Argentina e do México, o Brasil conseguiu desenvolver uma indústria cinematográfica, mesmo que precária, houve, com relação às fontes escritas, uma preocupação por parte dos críticos, no sentido de resgatar essa história através da coleta de depoimentos de cineastas das primeiras décadas do século, ainda vivos; da fundação de cinematecas ${ }^{3}$ ou no regate também de roteiros e de títulos de filmes. Na introdução de sua Filmografia do Cinema Brasileiro, Jean Claude Bernadet comenta a importância da recuperação desse cinema no qual "uma certa elite mundana e de poder pode encontrar uma imagem de si própria". Prossegue, referindo-se aos filmes de ficção: "se, para as épocas mais recuadas, o levantamento não pode ser feito através dos filmes, pois na sua esmagadora maioria perderam-se, que seja feito pelos vestígios que sobraram"4.

$\mathrm{O}$ esforço de pesquisa por parte de nossos críticos e historiadores prossegue na recuperação dessa história perdida. Exemplo disso é o recente artigo de José Inácio de
Melo Souza, pesquisador da Cinemateca, revisando as origens do cinema brasileiro ${ }^{5}$.

\section{ETAPAS HISTÓRICAS}

A história do cinema brasileiro desenvolveu-se em etapas significantes separadas por crises às vezes longas. Paulo Emílio procurou traçar criticamente, num texto bastante conhecido, a trajetória do cinema brasileiro, dentro do subdesenvolvimento: "O cinema é incapaz de encontrar dentro de si próprio energias que lhe permitam escapar à condenação do subdesenvolvimento, mesmo quando uma conjuntura particularmente favorável suscita uma expansão na fabricação de filmes"6.

\begin{abstract}
Além dessa característica de ser um cinema dentro do subdesenvolvimento, sem financiamentos ou proteção estatal, nosso cinema demonstrou, nas fases de maior sucesso comercial, uma característica básica: o modo artesanal de ser.
\end{abstract}

Paulo Emílio também traçou um panorama do cinema brasileiro, no qual estabelece cinco épocas, para o período 1896/ 19667. Vamos retomar essas etapas de forma sintética.

Os dados colhidos pelo pesquisador demonstram que "os dez primeiros anos de cinema no Brasil são muito pobres". Rio de Janeiro e São Paulo eram os centros onde se concentravam as salas fixas de projeção e, além disso, sem que se alterasse esse quadro de pouca significação, existiram numerosos cinemas ambulantes.

Esse ritmo lento do cinema brasileiro na época devia-se ao atraso em matéria de eletricidade.

3. Nitrato: documentário de ex-alunos da ECA, com depoimento de Paulo Emílio, suficiente para denunciar o drama da falta de verbas na conservação da Cinemateca Brasileira, vítima de seguidos incêndios.

4. BERNADET, J.C. Filmografia do cinema brasileiro 1900-1935. Jornal O Estado de São Paulo. Comissão de Cinema, 1979.

5. SOUZA, José Inácio de Melo. Descoberto o primeiro filme brasileiro. Revista USP (19). Dossiê Cinema Brasileiro. São Paulo: USP, 1993, p. 170-173.

6. GOMES, Paulo Emf́lio Salles. Cinema: trajetória no subdesenvolvimento. op. cit.

7. O texto foi recuperado por Maria Rita Galvão e Jean Claude Bernardet a partir de três fontes no livro de textos de Paulo Emílio, op. cit. p.39-69. 
Nesse primeiro período despontam notícias sobre algumas comédias curtas e filmes sobre crimes que abalaram a sociedade da época, além de filmes-revistas de atualidade política. Apesar do ritmo lento, há um certo brilho nesta primeira etapa apontada por Paulo Emílio.

A segunda época, que vai de 1912 a 1922, registra a realização de muitos filmes, mas também com limitações. Inicia-se nessa etapa o acesso difícil da produção nacional aos circuitos de salas que já se definem como monopólios para exibição de filmes estrangeiros. Além disso a produção de filmes nacionais de enredo foi precária e escassa. "Os sessenta filmes posados encerram uma porcentagem considerável de curtas metragens, destinadas às vezes à mais variada publicidade comercial, indo desde a propaganda de loteria até à divulgação de remédios contra a sífilis"8.

De 1923 a 1933, terceira época, surgem duas importantes revistas: Paratodos e Selecta, veículos que iniciam a primeira campanha sistemática em favor de nosso cinema.

Outro fato significativo nesta terceira época é o aparecimento de diversos focos de realização cinematográfica em vários pontos do Brasil como Campinas; Recife, o maior em quantidade de produção; Belo Horizonte, marcado pelo famoso ciclo de Cataguases e Rio Grande do Sul.

Em 1933 foi lançado o filme $A$ voz do carnaval, de Adhemar Gonzaga e Humberto Mauro, no estúdio da Cinédia, Rio de Janeiro, com a estréia da cantora Carmem Miranda. Este filme foi lançado num momento de crise para o cinema nacional e apontava para uma das principais direções que tomaria o cinema brasileiro na sua luta pela sobrevivência, considerando um mercado tomado pelo cinema estrangeiro: o musical com lançamentos de música de carnaval.
Na quarta época (1933 a 1949), com exceção de um projeto industrial paulista frustrado, a produção na sua maioria é carioca. Destacam-se algumas realizações de Humberto Mauro, através da produtora Brasil Vita Film, de Carmem Santos, atriz e empresária. O filme mais importante dessa série foi Favela dos meus amores.

A Cinédia foi a companhia que absorveu a maior parte das produções cinematográficas, encontrando uma fórmula que garantiu a continuidade do cinema brasileiro durante duas décadas: a comédia musical carnavalesca ou a chanchada.

Paulo Emílio observa que o fenômeno da chanchada "repugnou os críticos e estudiosos. Contudo, um exame atento é possível que nos conduza a uma visão mais encorajante do que significou a popularidade de Mesquitinha, Oscarito, Grande Otelo, Ankito, Zé Trindade, Derci Gonçalves, Violeta Ferraz... Os personagens grotescos foram naturalmente o centro de gravidade da chanchada, o que não impediu que se configurasse pelo menos um tipo de galã: Anselmo Duarte" 9 .

Durante esse período a chanchada foi o gênero mais vivo no cinema nacional embora tenha havido exceções como $\mathbf{O}$ Ébrio de Vicente Celestino e Gilda de Abreu, com expressivo êxito de público.

Realmente, os filmes de Gilda de Abreu foram exceções na medida em que o melodrama musical não chegou a fazer escola no Brasil daquele período.

A quinta época (1950 a 1966) inicia-se com a transferência do eixo das produções para São Paulo, através da concentração de um aparato tecnológico sofisticado, construção de estúdios e contratação de técnicos e diretores italianos e ingleses, inclusive $\mathrm{Al}$ berto Cavalcanti, que se ilustrara no cinema inglês e francês. 
Nesse sentido, após a fracassada primeira experiência que foi a Maristela, fundou-se a Vera Cruz, em 1949. Lançou-se o esquema do estrelismo e foram realizados filmes importantes com uma dramaturgia européia.

Infelizmente, esse empreendimento durou poucos anos, em função principalmente da falta de experiência administrativa nesse setor e em 1954 já estava falido.

Teve um público considerável e os dois últimos filmes merecem destaque pelo fato de terem aberto dois meios de produção brasileiros para os próximos anos: $\mathbf{O}$ cangaceiro de Lima Barreto, que inaugurou a temática do cangaço, e Sai da frente de Mazzaroppi, o qual cria um ciclo de comédias brejeiras em que ele próprio é produtor, diretor e protagonista sob a pele do personagem caipira Genésio Arruda.

Paulo Emílio resume os projetos de industrialização cinematográfica paulista: "Esse período da cinematografia paulista foi rico em filmes e acontecimentos: os meios intelectuais, artísticos e de negócios tomaram afinal conhecimento do nosso cinema, que ficou sendo assunto constante nas rodas.

Não há dúvida de que as promessas de melhoria do padrão técnico e artístico foram razoavelmente cumpridas, a partir de Caiçara, confirmando-se em muitos outros: Ângela, O comprador de fazendas, Terra é sempre terra, Veneno, Sinhá moça, Uma pulga na balança..." 10 .

O fim da Vera Cruz não significou o fim da produção industrial no período. Pelo contrário, até o final dos anos 50 a produção alcança a média de mais de cinqüenta filmes anuais.

Há uma diversificação dos gêneros, como por exemplo, $\mathbf{O}$ saci de Rodolfo Nanni, que inicia o gênero juvenil no cinema brasileiro, ou filmes como Agulha no palheiro do crítico Alex Viany e Amei um bicheiro de Jorge Ileli, que tomam como contexto a crônica urbana e onde se inscrevem a comédia e o drama.

\section{O CINEMA NOVO DOS ANOS 60}

Além do revigoramento da chanchada carioca, surgem filmes influenciados pelo neo-realismo italiano, como Rio $\mathbf{4 0}$ graus de Nélson Pereira dos Santos, no Rio de Janeiro, ou o $\mathbf{O}$ grande momento de Roberto Santos, em São Paulo, marcos de uma nova visão crítica da realidade brasileira, a partir do cinema.

Destaca-se nesse período o ciclo baiano, a partir de dois filmes: Bahia de Todos os Santos de Alex Viany e $\mathbf{O}$ pagador de promessas de Anselmo Duarte, filmados na Bahia, ambos muito bem realizados, sendo que o segundo foi Palma de Ouro em Cannes.

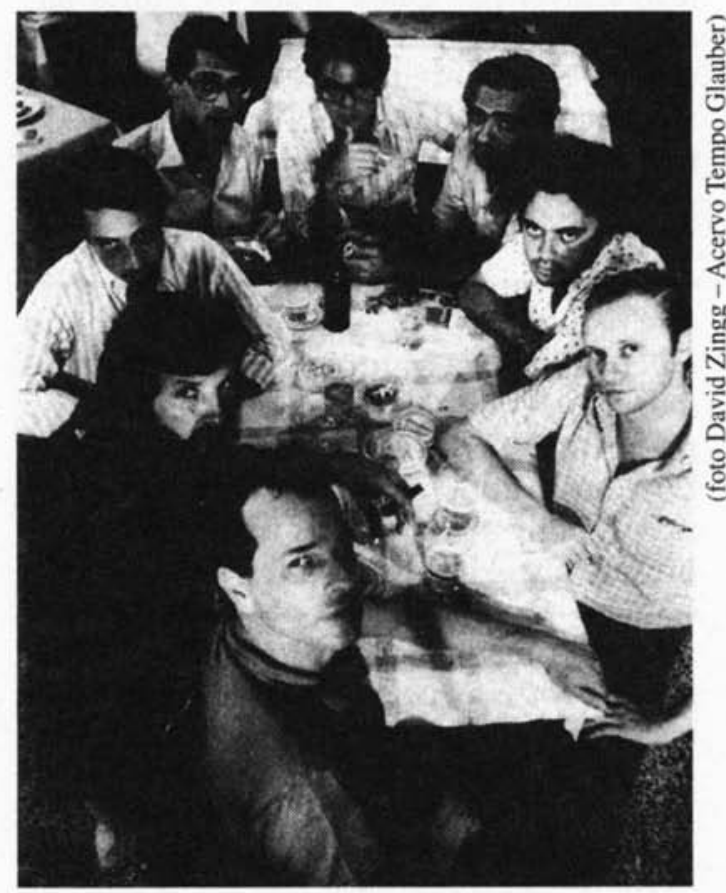

Da esq. para a dir.: Nelson Pereira dos Santos, Ruy Guerra, Joaquim Pedro de Andrade, Walter Lima Jr., Zelito Viana, Luís Carlos Barreto, Glauber e Leon Hirszman. 
O filme Deus e o diabo na Terra do Sol de Gláuber Rocha insere-se no tão polêmico movimento carioca denominado Cinema Novo.

Paulo Emílio foi um crítico entusiasta do Cinema Novo. Na Panorâmica do cinema brasileiro demonstra isso: "É a erupção do chamado Cinema Novo, movimento notadamente carioca, que engloba de forma pouco discriminada tudo o que se fez de melhor - em matéria de ficção ou documentário - no moderno cinema brasileiro. Seu quadro de excelentes diretores de fitas de enredo já é grande tendendo sempre a aumentar dia-a-dia: Glaúber Rocha, Paulo César Sarraceni, Joaquim Pedro de Andrade, Ruy Guerra, Luís Sérgio Person, Leon Hirzman, Carlos Diegues, Sérgio Ricardo, Walter Lima Júnior... Depois de Cinco vezes favela, filme desigual mas revelador, produzido em 1962, tornou-se o Cinema Novo o responsável por quase todos os filmes nacionais importantes que têm aparecido nos últimos anos: Os cafajestes, Porto das caixas, Deus e o diabo na Terra do Sol, Os fuzis, Esse mundo é meu, Menino de engenho, A grande cidade, $O$ desafio, São Paulo S.A., O padre e a moça..."'l.

O Cinema Novo brasileiro está ligado ao cinemanovismo mundial dos anos 60 . Ele não é, portanto, exclusivo; manifesta-se nos principais centros cinematográficos, buscando uma nova dramaturgia para aprofundar a análise das respectivas realidades históricas.

A primeira característica desses Cinemas Novos é a crítica aos padrões do cinema industrial, principalmente norte-ameri- cano, que estava mais voltado para o entretenimento.

Além disso, de uma forma geral, os autores do cinemanovismo propunham o realismo crítico. Ismail Xavier sintetiza, num artigo sobre o cinema político, os objetivos dos autores desse movimento na América Latina: "Queriam uma dramaturgia liberta de clichês, impulsionadora da expressão cultural, sem as censuras do aparato industrial, estimuladora de uma consciência crítica em face da experiência contemporânea. Sem descartar as emoções e o divertimento, entendiam que a dimensão política das novas poéticas exigia uma linguagem que deveria ir além da transformação dos problemas em espetáculo. O que significava a construção de uma linguagem capaz de 'fazer pensar'..."12. O Cinema Novo foi interrompido em seu processo pelo AI-5, durante o regime militar no Brasil.

Movimentos como Cinema do Lixo em São Paulo, iniciado na mesma época, foram analisados de forma amarga. Exemplo é a visão de Paulo Emílio: "Conglomerado heterogêneo de artistas nervosos da cidade e de artesãos do subúrbio, o Lixo propõe um anarquismo sem qualquer rigor ou cultura anárquica e tende a transformar a plebe em ralé, o ocupado em lixo. (...) Isolada na clandestinidade, essa última corrente de rebeldia cinematográfica compõe de certa forma um gráfico de desespero juvenil no último qüinqüênio"13.

Apesar de seu espírito crítico, e talvez por isso mesmo, Paulo Emílio sempre foi otimista com relação ao nosso cinema, visando ao fim do subdesenvolvimento e a uma "reanimação sem milagre da vida brasileira", através da revisão do nosso processo cultural.

11. GOMES, Paulo Emílio Salles. op. cit. p.84.

12. XAVIER, Ismail. Cinema político e gêneros tradicionais, a força e os limites da matriz melodramática. Revista da USP (19), Dossiê Cinema Brasileiro. São Paulo: USP, 1993, p.115-116.

13. GOMES, Paulo Emílio. op. cit. p. 87. 